\title{
Ecofisiologia de plantas jovens de mogno-africano submetidas a deficit hídrico e reidratação
}

\author{
Marcos Paulo Ferreira de Albuquerque ${ }^{(1)}$, Fabrícia Kelly Cabral Moraes(1), Rodolfo Inácio Nunes Santos(1), \\ Gledson Luiz Salgado de Castro(1), Edson Marcos Leal Soares Ramos ${ }^{(2)}$ e Hugo Alves Pinheiro(1)
}

\begin{abstract}
(1)Universidade Federal Rural da Amazônia, Instituto Socioambiental e dos Recursos Hídricos, Avenida Presidente Tancredo Neves, no 2.501, CEP 66077-530 Belém, PA. E-mail: agroalbuquerque@hotmail.com, fkcabralm@hotmail.com, rodolfo_inacio85@yahoo.com.br, gledson_cliff@hotmail.com, hugo.pinheiro@ufra.edu.br (2)Universidade Federal do Pará, Instituto de Ciências Exatas e Naturais, Rua Augusto Corrêa, noo 01, CEP 66075-110 Belém, PA. E-mail: ramosedson@gmail.com
\end{abstract}

\begin{abstract}
Resumo - O objetivo deste trabalho foi avaliar a capacidade de plantas jovens de mogno-africano (Khaya ivorensis) em recuperar seu status hídrico e trocas gasosas após período de deficit hídrico. Plantas com aproximadamente 315 dias, irrigadas (controle) e não irrigadas, foram avaliadas aos 14 dias da suspensão da irrigação e após um, três e sete dias da retomada da irrigação (reidratação). No dia 14, o potencial hídrico foliar de antemanhã ( $\left.\Psi_{\text {am }}\right)$ das plantas estressadas foi reduzido a -2,66 MPa. Com a restrição hídrica, foram observadas reduções significativas no conteúdo relativo de água na antemanhã (redução de 32\%), na taxa de assimilação líquida de $\mathrm{CO}_{2}(90 \%)$, na condutância estomática $(95 \%)$, na transpiração $(93 \%)$ e na razão entre concentração intercelular e ambiental de $\mathrm{CO}_{2}(37 \%)$. Durante a reidratação, o status hídrico das plantas estressadas foi restabelecido após três dias. As trocas gasosas também se restabeleceram, mas de forma mais lenta que o status hídrico. Sob deficit hídrico, a concentração de prolina aumentou e a de carboidratos solúveis totais diminuiu. Plantas jovens de mogno-africano são tolerantes ao deficit hídrico moderado.
\end{abstract}

Termos para indexação: Khaya ivorensis, ajustamento osmótico, prolina, solutos compatíveis, status hídrico, trocas gasosas.

\section{Ecophysiology of young African mahogany plants subjected to water deficit and rewetting}

\begin{abstract}
The objective of this work was to evaluate the capacity of young plants of African mahogany (Khaya ivorensis) to recover their water status and gas exchange after water deficit. Plants with approximately 315 days, irrigated (control) and non-irrigated, were evaluated after water was withheld for 14 days, and after one, three, and seven days of irrigation resumption (rehydration). On day 14, the predawn leaf water potential ( $\left.\Psi_{\text {am }}\right)$ of stressed plants was reduced to -2.66 MPa. With water deficit, significant decreases were observed in predawn relative water content (32\% reduction), in net assimilation rate of $\mathrm{CO}_{2}(90 \%)$, in stomatal conductance $(95 \%)$, in transpiration (93\%), and in intercellular to ambient ratio of $\mathrm{CO}_{2}$ concentration (37\%). During rehydration, the water status of stressed plants was recovered after three days. Gas exchange was also recovered, but in a slower rate than water status. Under water deficit, proline concentration increased and total soluble carbohydrate concentration decreased. Young African mahogany plants are tolerant to moderate water deficit.
\end{abstract}

Index terms: Khaya ivorensis, osmotic adjustment, proline, compatible solutes, water status, gas exchange.

\section{Introdução}

As condições climáticas na região amazônica favorecem uma maior distribuição e frequência das chuvas entre dezembro e maio. Entre junho e novembro, as precipitações médias mensais não chegam a $100 \mathrm{~mm}$ (Rocha, 2001). No entanto, quando fenômenos meteorológicos, como E1 Niño e La Niña, ocorrem, a distribuição e a frequência das chuvas tende a variar consideravelmente (Davidson et al., 2012).

A redução do status hídrico em várias espécies lenhosas promove diminuições significativas na taxa de assimilação líquida do $\mathrm{CO}_{2}$ (A), na condutância estomática $\left(\mathrm{g}_{\mathrm{s}}\right)$ e na transpiração $(\mathrm{E})$, como observado em Mauritia vinifera (Calbo \& Moraes, 1997), Coffea canephora (Pinheiro et al., 2005), Eragrostis curvula (Colom \& Vazzana, 2001) e Minquartia guianensis (Liberato et al., 2006). Em geral, a redução na assimilação de carbono diminui a síntese de trioses fosfatadas, o que resulta na redução ou na paralisação do crescimento. Neste caso, é comum que o crescimento limite-se ao sistema radicular, numa estratégia de buscar a absorção de água em horizontes mais profundos do solo (Kozlowski \& Pallardy, 1997). 
A própria redução na condutância estomática em plantas desidratadas, com a consequente queda em A, é uma estratégia para reduzir a perda excessiva de água via transpiração.

Em algumas plantas lenhosas, que apresentam fortes reduções em $\mathrm{g}_{\mathrm{s}}$ e E quando expostas ao deficit hídrico, a ascensão de seiva via xilema pode ser favorecida pela síntese ou pelo acúmulo de solutos (orgânicos e inorgânicos) osmoticamente ativos no citosol celular (Nepomuceno et al., 2001). Entre os compostos osmoticamente ativos mais comuns, figuram a prolina (Szabados \& Savouré, 2010), a glicina betaína (Chen \& Murata, 2008) e os carboidratos solúveis totais (Sudachkova et al., 2002). O acúmulo desses compostos nas folhas diminui o potencial hídrico foliar $\left(\Psi_{\mathrm{w}}\right)$, o que aumenta a capacidade de absorção de água das plantas e atenua os efeitos do deficit hídrico no conteúdo relativo de água da planta (Pagter et al., 2005).

Plantas jovens de Swietenia macrophylla (Cordeiro et al., 2009) e Carapa guianensis (Gonçalves et al., 2009) toleram satisfatoriamente períodos de 15 a 30 dias de deficiência hídrica. Essas espécies pertencem à família Meliaceae e são típicas do bioma amazônico. Esses autores observaram que esses períodos de deficiência hídrica diminuíram o potencial hídrico foliar para valores entre -2,0 e -3,0 MPa, aproximadamente, e que o status hídrico de $C$. guianensis é recuperado mais rapidamente que as trocas gasosas. Esses resultados permitem inferir que plantas jovens de mogno-africano (Khaya ivorensis A. Chev.) toleram bem períodos curtos de deficit hídrico, já que esta também é uma espécie lenhosa da família Meliaceae. Contudo, esse tipo de estudo ainda não foi feito para K. ivorensis, embora esta seja uma espécie com ótima qualidade de madeira, que alcança preços elevados no mercado nacional e internacional. No caso de uma boa tolerância ao deficit hídrico, plantios comerciais em áreas sujeitas a períodos moderados de estiagem teriam sua viabilidade aumentada.

O objetivo deste trabalho foi avaliar a capacidade de plantas jovens de mogno-africano em recuperar seu status hídrico e trocas gasosas após período de deficit hídrico.

\section{Material e Métodos}

Plantas jovens de mogno-africano, com aproximadamente 180 dias de idade, foram selecionadas a partir de viveiro certificado, localizado no Município de Benevides, PA. A seleção das mudas foi realizada com base na uniformidade em altura $e$ número de folhas e de folíolos.

Após sete dias de aclimatação em casa de vegetação, as mudas foram transferidas para vasos de polietileno (31 cm de altura por $35 \mathrm{~cm}$ de diâmetro), com $30 \mathrm{~L} \mathrm{de}$ capacidade, preenchidos com $20 \mathrm{~kg}$ de um Latossolo Amarelo de textura média. As mudas foram irrigadas diariamente, tendo-se reposto a água perdida por evapotranspiração, cujo volume foi estimado por meio da pesagem das unidades experimentais (planta + vaso + substrato). As plantas daninhas foram controladas manualmente.

Após 60 dias do transplantio das mudas para os vasos, e levando-se em conta a análise química do substrato, foram aplicados $0,48 \mathrm{~g}$ de $\mathrm{K}_{2} \mathrm{O}$ e 2,8 $\mathrm{g}$ de ureia por vaso, diretamente sobre o solo (Brasil \& Cravo, 2007). Trinta dias após esta fertilização, aplicou-se a solução nutritiva completa de Hoagland \& Arnon, modificada por Epstein (1975). Em cada vaso, foi aplicado $1 \mathrm{~L}$ desta solução, fracionado em quatro aplicações de $250 \mathrm{~mL}$, ao longo de 30 dias.

Durante o experimento, as médias de temperatura $\left(\mathrm{T}_{\mathrm{ar}}, 30^{\circ} \mathrm{C}\right)$ e umidade relativa do ar (UR, 88\%) foram registradas por meio de termohigrômetro, modelo 5203 (Incoterm, Porto Alegre, RS). A temperatura da folha $\left(T_{f}\right)$ foi registrada por meio de sensor de temperatura acoplado à câmara de analisador de gases a infravermelho (LCpro, ADC Bioscientific Ltd., Hoddesdon, Reino Unido). As médias de temperatura do ar em termômetro bulbo seco e úmido, bem como a $T_{\mathrm{f}}$ foram utilizadas para calcular o deficit de pressão de vapor d'água entre folha e atmosfera (Landsberg, 1986), cujo valor médio foi de $2,41 \mathrm{kPa}$. Estes registros climáticos foram realizados durante a manhã (das $7 \mathrm{~h}$ às $12 \mathrm{~h}$ ), paralelamente às medições das trocas gasosas.

Quando as plantas alcançaram 315 dias de idade, elas foram subdivididas em dois grupos: plantas irrigadas (tratamento controle) e não irrigadas (tratamento de deficit hídrico). As plantas do tratamento controle continuaram a receber irrigação diária conforme descrito, e as plantas do tratamento com deficit hídrico tiveram sua irrigação completamente suspensa, de forma que o estresse foi resultante do gradativo esgotamento da água do solo. $\mathrm{O}$ experimento foi instalado em delineamento de blocos ao acaso, com dois tratamentos (controle e deficit hídrico) e seis 
repetições, tendo-se considerado os vasos - com uma planta cada um - como unidade experimental.

Os efeitos do deficit hídrico foram avaliados quando a taxa de assimilação líquida do $\mathrm{CO}_{2}$ atingiu valores próximos de zero, o que ocorreu após 14 dias da suspensão da irrigação. Durante este período, foram avaliados o status hídrico das plantas (potencial hídrico na antemanhã, $\Psi_{\text {am }}$ e conteúdo relativo de água na antemanhã, $\mathrm{CRA}_{\mathrm{am}}$ ) e as trocas gasosas (taxa de assimilação líquida do $\mathrm{CO}_{2}, \mathrm{~A}$; condutância estomática, $\mathrm{g}_{\mathrm{s}}$; transpiração, E; e razão entre concentração intercelular e atmosférica de $\mathrm{CO}_{2}, \mathrm{C}_{\mathrm{i}} / \mathrm{C}_{\mathrm{a}}$ ). Foram coletadas amostras foliares para avaliação das concentrações foliares de carboidratos solúveis totais, amido, prolina e glicina betaína. Airrigação foi retomada às $17 \mathrm{~h}$ do dia 14 , e a capacidade de recuperação das plantas estressadas foi avaliada nos dias subsequentes (período de reidratação).

A recuperação do status hídrico e das variáveis bioquímicas foi avaliada nos dias 15, 17 e 21, e a recuperação das trocas gasosas foi avaliada nos dias 15 , 17,19 e 21 . A amostragem foi feita em folíolos maduros e sadios da terceira ou da quarta folha a partir do ápice. $\mathrm{O} \Psi_{\text {am }}$ e o CRA am foram avaliados entre $4 \mathrm{~h} 30$ e $5 \mathrm{~h} 30$, enquanto as avaliações das trocas gasosas e a coleta de amostras para as análises bioquímicas foram realizadas entre $10 \mathrm{~h}$ e 11h30. Este horário foi definido de acordo com os resultados obtidos com a curva diurna de trocas gasosas para a espécie (Cunha, 2010). As amostras para as análises bioquímicas foram coletadas após a avaliação das trocas gasosas e imediatamente secas em estufa de circulação forçada de ar, a $50^{\circ} \mathrm{C}$, até massa constante. Em seguida, as amostras foram trituradas a pó fino, armazenadas em frascos de vidro hermeticamente fechados e acondicionadas em dessecador de vidro, até o momento das análises.

$\mathrm{O} \Psi_{\text {am }}$ foi determinado por meio de câmara de pressão do tipo Scholander, modelo 670 (Pms Instrument Co., Albany, OR, EUA), conforme descrito por Pinheiro et al. (2008), e o $\mathrm{CRA}_{\mathrm{am}}$ foi avaliado segundo Slavick (1974). As variáveis $A, g_{s}, E$ e $C_{i} / C_{a}$ foram avaliadas por meio de analisador de gases a infravermelho (LCpro, ADC Bioscientific Ltd., Hoddesdon, Reino Unido), sob concentrações naturais de $\mathrm{CO}_{2} \mathrm{e}$ radiação fotossinteticamente ativa (RFA) fixada em $957 \mu \mathrm{mol} \mathrm{m} \mathrm{m}^{-2} \mathrm{~s}^{-1}$ - valor que representa a média de RFA para o horário das medições no local do experimento. As medições de trocas gasosas foram realizadas em dois folíolos adjacentes, e a média destas foi utilizada para análise estatística e preparação das figuras.

As concentrações de carboidratos solúveis totais e de amido foram determinadas conforme Dubois et al. (1956). A concentração de prolina foi avaliada pelo método de Bates et al. (1973), e a concentração de glicina betaína, pelo método de Grieve \& Grattan (1983).

Os resultados foram submetidos à análise de variância, tendo-se considerado o delineamento de blocos ao acaso em arranjo fatorial $2 \times 5$ (dois regimes hídricos e cinco dias de avaliação), para trocas gasosas, e $2 \times 4$ (dois regimes hídricos e quatro dias de avaliação), para status hídrico e variáveis bioquímicas. Os contrastes, para plantas de um mesmo regime hídrico avaliadas em diferentes dias, foram comparados pelo teste de Tukey, a 5\% de probabilidade. Os contrastes, para plantas de diferentes tratamentos avaliadas no mesmo dia (efeito do estresse), foram avaliados pelo teste $\mathrm{t}$ pareado, a $5 \%$ de probabilidade. As análises estatísticas foram realizadas com o programa Minitab, versão 14.1 (Minitab Inc., State College, PA, EUA).

\section{Resultados e Discussão}

No dia 14, as plantas irrigadas apresentaram $\Psi_{\text {am }}$ de $-0,23 \pm 0,04 \mathrm{MPa}$ e $\mathrm{CRA}_{\text {am }}$ de $90 \%$. Nas plantas sob deficit hídrico, o $\Psi_{\text {am }}$ foi de -2,66 $\pm 0,04 \mathrm{MPa}$ e o $\mathrm{CRA}_{\mathrm{am}}$ de $62 \%$ (Figura 1). Nas plantas não irrigadas, foram observadas reduções expressivas nos valores de A $(90 \%), g_{s}(95 \%)$ e $E(93 \%)$, em comparação às plantas controle (Figura 2). Uma redução menos expressiva, de $37 \%$, foi observada em $\mathrm{C}_{\mathrm{i}} / \mathrm{C}_{\mathrm{a}}$. Esses resultados evidenciam forte sensibilidade do aparato fotossintético da espécie ao deficit hídrico. Eles também dão suporte à ideia de que o mogno-africano de fato controla eficientemente a perda de água via transpiração, regulando a abertura estomática, conforme observado em plantas jovens de $S$. macrophylla (Cordeiro et al., 2009) e C. guianensis (Gonçalves et al., 2009), ambas da mesma família botânica que $K$. ivorensis (Meliaceae).

De acordo com Flexas \& Medrano (2002), a redução em A, em plantas submetidas a deficit hídrico, pode ocorrer por diferentes razões, tais como limitação estomática ao influxo de $\mathrm{CO}_{2}$, danos ao aparato fotoquímico da fotossíntese, redução na síntese de ATP, e diminuição na atividade da Rubisco 
(Ribulose-1,5-bisfosfato carboxilase oxigenase) ou em sua taxa de regeneração.

$\mathrm{O}$ reestabelecimento completo de $\mathrm{C}_{\mathrm{i}} / \mathrm{C}_{\mathrm{a}}$ ocorreu após um dia da retomada da irrigação, enquanto a recuperação completa de A ocorreu somente após sete dias (Figura 2). Esse maior tempo para recuperação em A é um indício de que pode ter havido danos ao aparato fotoquímico e/ou bioquímico de fixação de $\mathrm{CO}_{2}$ das plantas sob estresse, e que estes danos
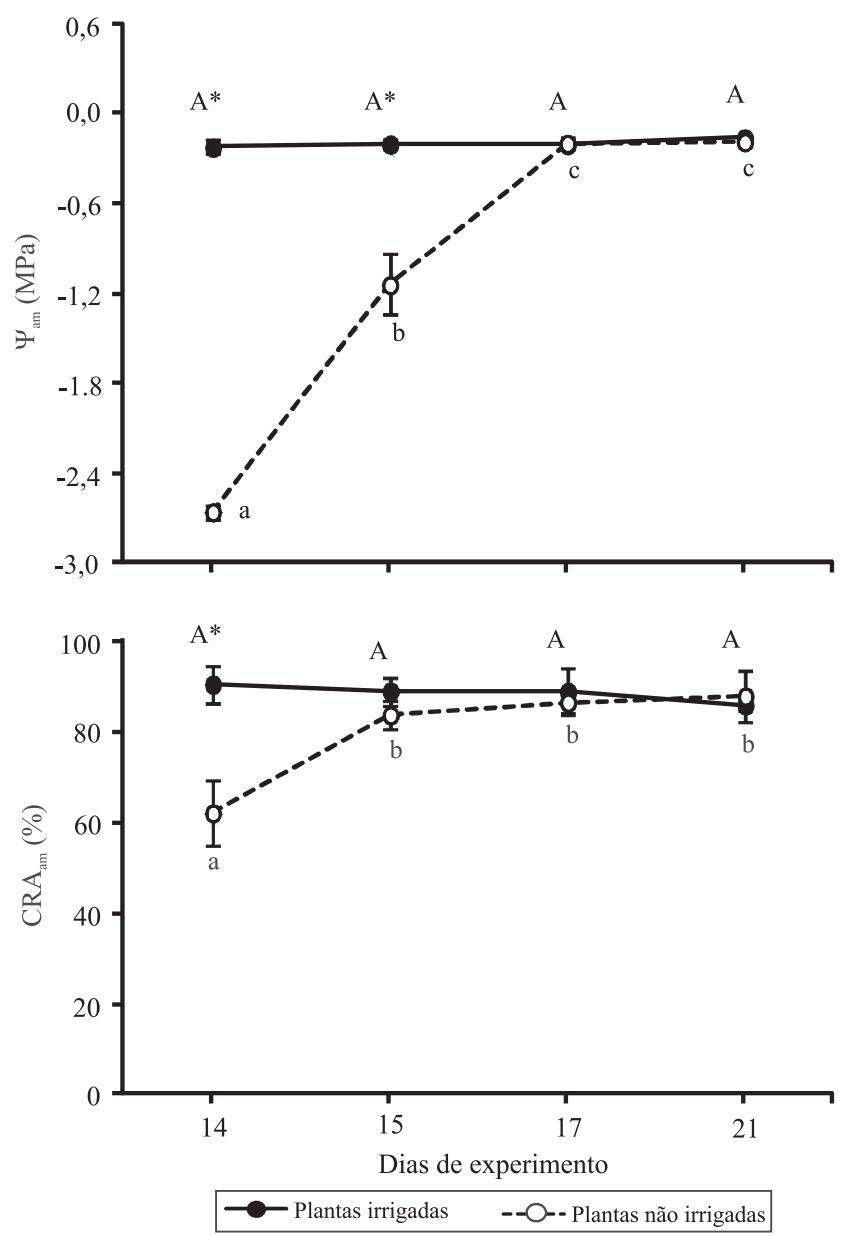

Figura 1. Potencial hídrico $\left(\Psi_{\mathrm{am}}\right)$ e conteúdo relativo de água $\left(\mathrm{CRA}_{\mathrm{am}}\right)$, na antemanhã, em plantas de mogno-africano irrigadas e não irrigadas, submetidas, a partir do dia 14, à reidratação. Os pontos representam as médias \pm desviopadrão. Médias seguidas de letras iguais, maiúsculas para as plantas irrigadas e minúsculas para as não irrigadas, não diferem pelo teste de Tukey, a $5 \%$ de probabilidade. *Diferença entre plantas irrigadas e não irrigadas, avaliada no mesmo dia, significativa pelo teste t pareado, a $5 \%$ de probabilidade. estariam mais relacionados à redução observada em A do que à limitação estomática ao influxo de $\mathrm{CO}_{2}$ (Flexas \& Medrano, 2002; Lawlor \& Cornic, 2002). Comparativamente, a redução na taxa de assimilação de $\mathrm{CO}_{2}$, em plantas de $C$. canephora submetidas a $\Psi_{\text {am }}$ de $-2,38 \mathrm{MPa}$, foi decorrente de danos à maquinaria de fixação de $\mathrm{CO}_{2}$, uma vez que foram observados incrementos na concentração intercelular de $\mathrm{CO}_{2}$ e apenas pequenas alterações nas variáveis de fluorescência da clorofila $a$, nas plantas estressadas (DaMatta et al., 2002).

Em consequência da redução em $\mathrm{A}$, as plantas não irrigadas apresentaram expressivo decréscimo (70\%) na concentração foliar de carboidratos solúveis totais, no dia 14 (Figura 3). Porém, não houve alteração significativa na concentração de amido, nessas plantas. Esses resultados são indicativos de que as plantas de mogno-africano, sob condições de estresse hídrico, investem parte das trioses fosfatadas produzidas pela fotossíntese (mesmo com baixa A) para a manutenção dos conteúdos de amido, e utilizam a parte restante dessas trioses para a respiração foliar. Esta partição de assimilados pode constituir uma estratégia de sobrevivência da planta, pois garante reserva de carboidratos para a respiração, quando a produção de assimilados diminui, ao final da tarde, ou cessa, durante a noite. Além da respiração, é comum que as plantas utilizem parte dos assimilados produzidos pela fotossíntese ou oriundos da degradação foliar do amido para estimular o crescimento do sistema radicular, sob condições de estresse, na tentativa de possibilitar uma maior exploração da água do solo (Pinheiro et al., 2005).

A concentração foliar média de prolina, nas plantas irrigadas, avaliadas no dia 14 , foi de $2,73 \mu \mathrm{mol} \mathrm{g}^{-1}$ MS. Nas plantas não irrigadas, esse valor foi de

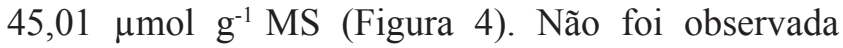
alteração significativa na concentração de glicina betaína, em consequência dos tratamentos. Contudo, para carboidratos solúveis totais, as plantas estressadas apresentaram redução significativa (Figura 3). Embora a ocorrência de um possível ajustamento osmótico não tenha sido avaliada neste experimento, o expressivo aumento (de aproximadamente 20 vezes) na concentração foliar de prolina é um forte indício de que plantas estressadas desta espécie podem realiza-lo. Este acúmulo de prolina deve ter sido resultante da síntese "de novo" deste composto, por meio da rota metabólica que utiliza o ácido glutâmico como 
precursor, com envolvimento da ação coordenada das enzimas sintetase e redutase da pirrolina-5-carboxilato (Szabados \& Savouré, 2010). Resultado similar foi observado por Silva (2009), que constatou aumento expressivo nas concentrações de prolina, em plantas jovens de $C$. guianensis submetidas a deficit hídrico. Entretanto, este autor também relatou aumento nos conteúdos de glicina betaína, nessa espécie, o que não foi observado para $K$. ivorensis, no presente trabalho.

Após a retomada da irrigação, tanto o $\Psi_{\text {am }}$ como o $\mathrm{CRA}_{\mathrm{am}}$ aumentaram significativamente nas plantas submetidas ao deficit hídrico. $\mathrm{O} \Psi_{\mathrm{am}}$ aumentou de -2,66 $\mathrm{MPa}$, no dia 14 , para $-1,14 \mathrm{MPa}$, no dia 15 , e o $\mathrm{CRA}_{\text {am }}$ foi de $62 \%$, no dia 14 , para $84 \%$, no dia 15 (Figura 1). Esses valores, no dia 15, já estavam muito próximos dos obtidos nas plantas controle, o que evidencia a rápida recuperação do status hídrico das plantas. Essa rápida recuperação também foi constatada em plantas jovens de $S$. macrophylla, cujos valores de $\Psi_{\text {am }}$ aumentaram de -3,52 MPa para $-0,07 \mathrm{MPa}$ após 12 horas da retomada da irrigação (Cordeiro et al., 2009). Carvalho (2005), ao avaliar plantas estressadas de Schizolobium amazonicum e $S$. parahyba, da família Fabaceae, observou aumento no CRA de 70 para $95 \%$, com poucos dias de reidratação. A rápida recuperação das plantas estressadas de mogno-africano indica que o deficit hídrico não causa danos irreversíveis à capacidade de absorção de água pelas raízes e ao seu transporte para a parte aérea.

A reidratação das plantas não irrigadas promoveu a recuperação completa em todas as variáveis de trocas gasosas $\left(\mathrm{A}, \mathrm{g}_{\mathrm{s}}, \mathrm{E}\right.$ e $\left.\mathrm{C}_{\mathrm{i}} / \mathrm{C}_{\mathrm{a}}\right)$. A recuperação completa de $\mathrm{C}_{\mathrm{i}} / \mathrm{C}_{\mathrm{a}}$ foi observada logo no dia 15 , ou seja, um dia após a retomada da irrigação (Figura 2). No entanto,
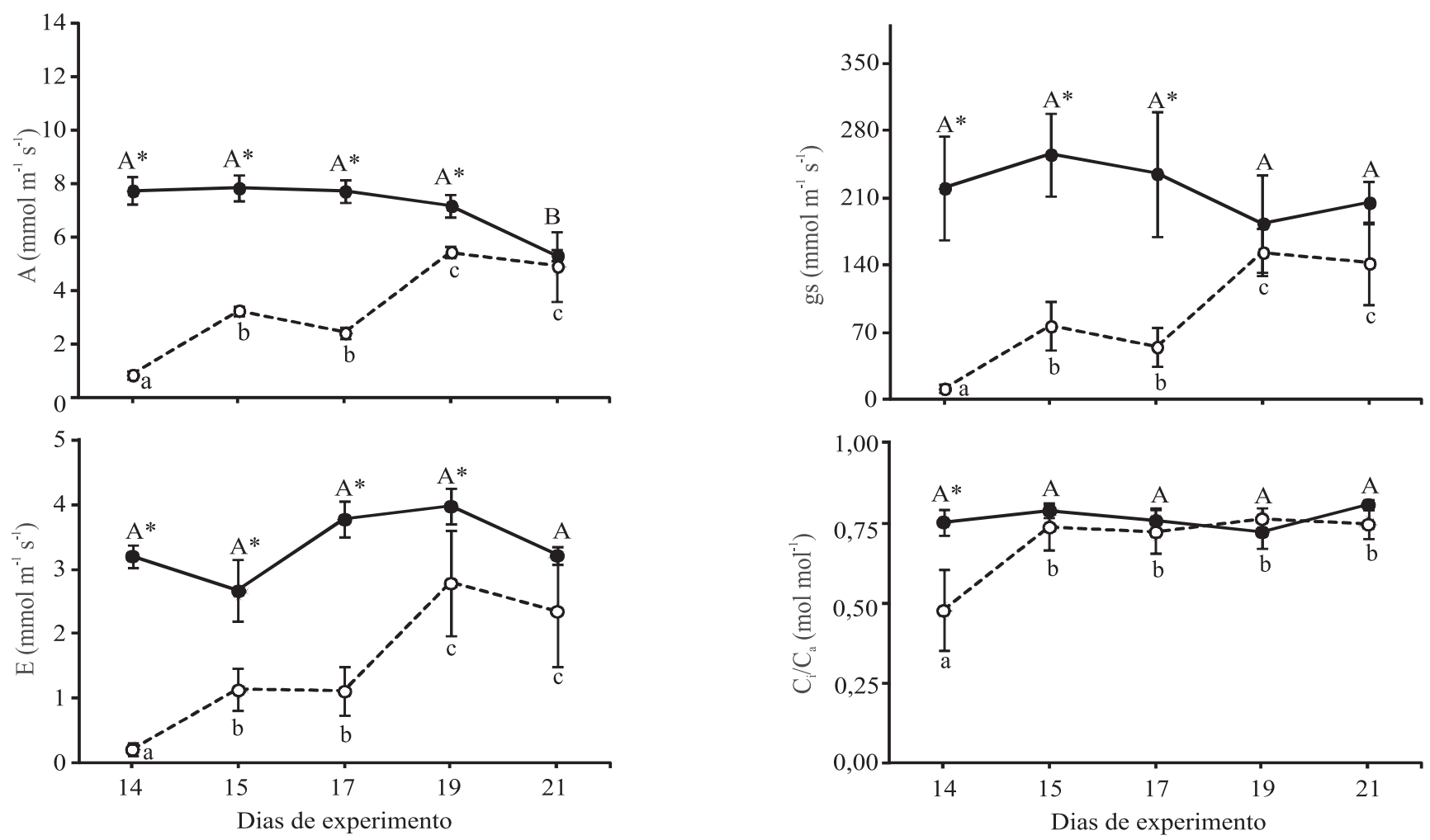

Plantas irrigadas

- Plantas não irrigadas

Figura 2. Taxas de assimilação líquida de $\mathrm{CO}_{2}(\mathrm{~A})$, condutância estomática (gs), transpiração (E) e razão entre concentração intercelular e ambiente de $\mathrm{CO}_{2}\left(\mathrm{C}_{\mathrm{i}} / \mathrm{C}_{\mathrm{a}}\right)$ em plantas de mogno-africano irrigadas e não irrigadas, submetidas à reidratação. Os pontos representam média \pm desvio-padrão. Médias seguidas de letras iguais, maiúsculas para as plantas irrigadas e minúsculas para as não irrigadas, não diferem pelo teste de Tukey, a 5\% de probabilidade. *Diferença entre plantas irrigadas e não irrigadas, avaliada no mesmo dia, significativa pelo teste t pareado, a 5\% de probabilidade. 
a recuperação das demais variáveis $\left(\mathrm{A}, \mathrm{g}_{\mathrm{s}}\right.$ e E) só se completou no dia 21, sete dias após a retomada da irrigação. Esses resultados são indicativos de que o mogno-africano pode, em um curto espaço de tempo, retomar seu metabolismo fotossintético e, com isso, recuperar a síntese de fotoassimilados, o que foi confirmado pelos valores encontrados para carboidratos solúveis totais no dia 15 e nos outros dias de avaliação (Figura 3). Resultados semelhantes foram obtidos em plantas de C. guianensis (Gonçalves et al.,
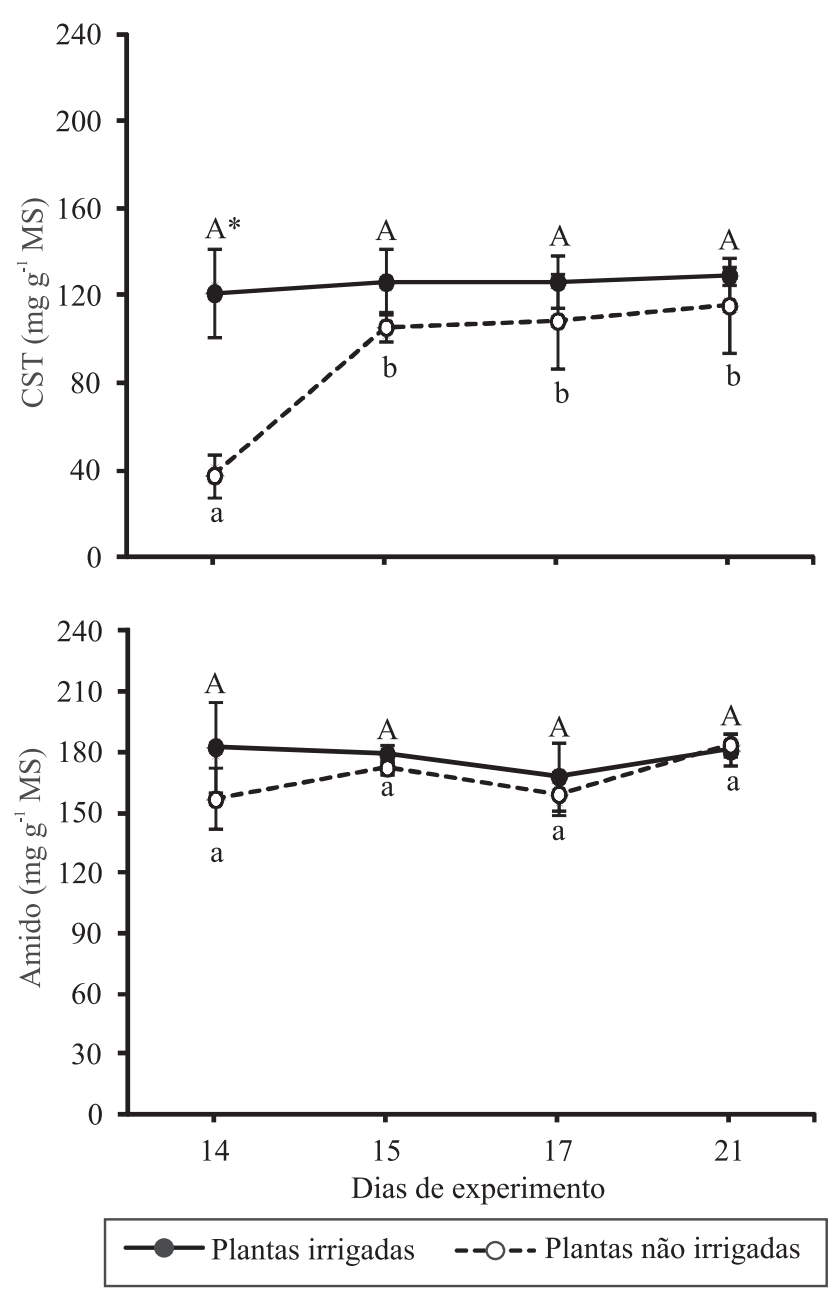

Figura 3. Concentrações foliares de carboidratos solúveis totais (CTS) e de amido em plantas de mogno africano irrigadas e não irrigadas submetidas à reidratação. Os pontos representam média \pm desvio-padrão. Médias seguidas de letras iguais, maiúsculas para as plantas irrigadas e minúsculas para as não irrigadas, não diferem pelo teste de Tukey, a 5\% de probabilidade. *Diferença entre plantas irrigadas e não irrigadas, avaliada no mesmo dia, significativa pelo teste $\mathrm{t}$ pareado, a $5 \%$ de probabilidade.
2009), Eucalyptus e Acacia spp. (Warren et al., 2011) submetidas à deficiência hídrica e à reidratação.

A concentração de prolina nas plantas submetidas à reidratação manteve-se alta no dia 15 , com média de 49,4 $\mu \mathrm{mol} \mathrm{g}{ }^{-1}$ MS (Figura 4). Esse valor não diferiu significativamente do registrado no dia $14\left(45,01 \mu \mathrm{mol} \mathrm{g}^{-1} \mathrm{MS}\right)$. Ao se considerar a possibilidade de o mogno-africano realizar ajustamento osmótico, a manutenção da alta concentração foliar de prolina
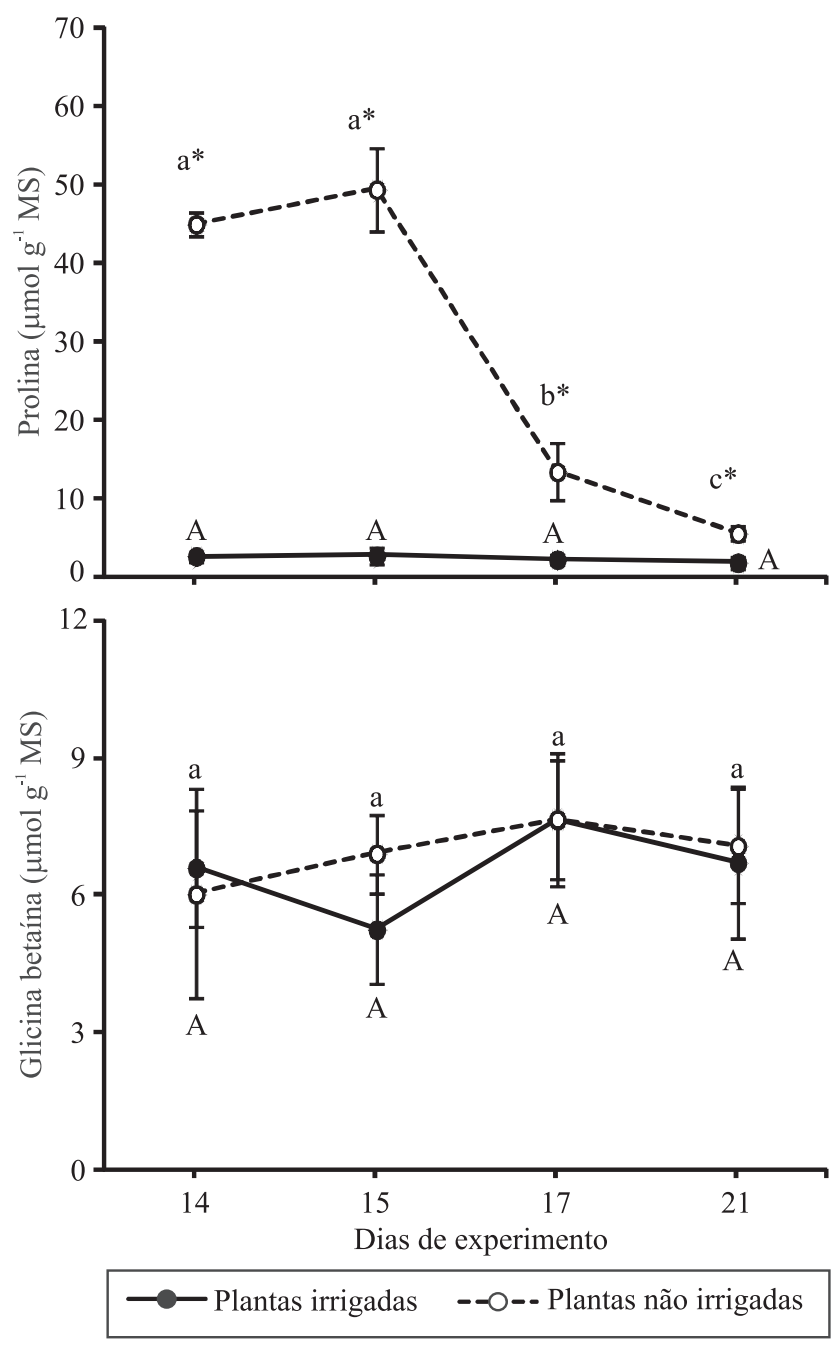

Figura 4. Concentrações foliares de prolina e glicina betaína em plantas de mogno africano irrigadas e não irrigadas submetidas à reidratação. Os pontos representam média \pm desvio-padrão. Médias seguidas de letras iguais, maiúsculas para as plantas irrigadas e minúsculas para as não irrigadas, não diferem pelo teste de Tukey, a 5\% de probabilidade. *Diferença entre plantas irrigadas e não irrigadas, avaliada no mesmo dia, significativa pelo teste $\mathrm{t}$ pareado, a $5 \%$ de probabilidade. 
imediatamente após a retomada da irrigação pode ter contribuído para a rápida recuperação de seu status hídrico. A partir do dia 15, quando o $\Psi_{\text {am }}$ e o $\mathrm{CRA}_{\mathrm{am}}$ das plantas previamente estressadas se igualaram aos das plantas permanentemente irrigadas, as concentrações foliares de prolina passaram a diminuir gradativamente. A metabolização da prolina pode ocorrer de diferentes formas no citosol, como, por exemplo, conversão em outros aminoácidos, utilização na síntese de proteínas e, principalmente, conversão em intermediários do cilco de Krebs, com estímulo à respiração e à síntese de ATP (Szabados \& Savouré, 2010).

\section{Conclusões}

1. Plantas jovens de mogno-africano apresentam alta sensibilidade estomática à deficiência hídrica, o que, aliado à expressiva acumulação de prolina, faz com que a espécie seja tolerante a estresses hídricos moderados.

2. O status hídrico das plantas e as trocas gasosas são plenamente recuperados após a reidratação das plantas, mas o status hídrico é restabelecido mais cedo que as trocas gasosas.

\section{Referências}

BATES, L.S.; WALDREN, R.P.; TEARE, I.D. Rapid determination of free proline for water-stress studies. Plant and Soil, v.39, p.205-207, 1973. DOI: 10.1007/BF00018060.

BRASIL, E.C.; CRAVO, M. da S. Interpretação dos resultados de análises de solo. In: CRAVO, M. da S.; VIÉGAS, I. de J.M.; BRASIL, E.C.; HOMMA, A.K.O. (Ed.). Recomendações de adubação e calagem para o Estado do Pará. Belém: Embrapa Amazônia Oriental, 2007. p.43-47.

CALBO, M.E.R.; MORAES, J.A.P.V. de. Fotossíntese, condutância estomática, transpiração e ajustamento osmótico de plantas de buriti submetidas a estresse hídrico. Revista Brasileira de Fisiologia Vegetal, v.9, p.117-123, 1997.

CARVALHO, C.J.R. de. Respostas de plantas de Schizolobium amazonicum [S. parahyba var. amazonicum] e Schizolobium parahyba [Schizolobium parahybum] à deficiência hídrica. Revista Árvore, v.29, p.907-914, 2005. DOI: 10.1590/S010067622005000600009 .

CHEN, T.H.H.; MURATA, N. Glycinebetaine: an effective protectant against abiotic stress in plants. Trends in Plant Science, v.13, p.499-505, 2008. DOI: 10.1016/j.tplants.2008.06.007.

COLOM, M.R.; VAZZANA, C. Drought stress effects on three cultivars of Eragrostis curvula: photosynthesis and water relations. Plant Growth Regulation, v.34, p.195-202, 2001. DOI: 10.1023/A:1013392421117.
CORDEIRO, Y.E.M.; PINHEIRO, H.A.; SANTOS-FILHO, B.G. dos; CORREAA, S.S.; DIAS-FILHO, M.B. Physiological and morphological responses of young mahogany (Swietenia macrophylla King) plants to drought. Forest Ecology and Management, v.258, p.1449-1455, 2009. DOI: $10.1016 /$ j. foreco.2009.06.054.

CUNHA, R.L.M. Comportamento ecofisiológico do mogno brasileiro (Swietenia macrophylla King) e do mogno africano (Khaya ivorensis A. Chev.) submetidos à adubação potássica nas condições edafoclimáticas de Igarapé Açu - PA, Amazônia Oriental. 2010. 122p. Tese (Doutorado) - Universidade Federal Rural da Amazônia, Belém.

DAMATTA, F.M.; LOOS, R.A.; SILVA, E.A.; LOUREIRO, M.E. Limitations to photosynthesis in Coffea canephora as a result of nitrogen and water availability. Journal of Plant Physiology, v.159, p.975-981, 2002. DOI: 10.1078/0176-1617-00807.

DAVIDSON, E.A.; ARAÚJO, A.C. de; ARTAXO, P.; BALCH, J.K.; BROWN, I.F.; BUSTAMANTE, M.M.C.; COE, M.T.; DEFRIES, R.S.; KELLER, M.; LONGO, M.; MUNGER, J.W.; SCHROEDER, W.; SOARES-FILHO, B.S.; SOUZA, C.M.; WOFSY, S.C. The Amazon basin in transition. Nature, v.481, p.321-328, 2012. DOI: 10.1038/nature10717.

DUBOIS, M.; GILLES, K.A.; HAMILTON, J.K.; REBERS, P.A.; SMITH, F. Colorimetric method for determination of sugars and related substances. Analytical Chemistry, v.28, p.350-356, 1956. DOI: $10.1021 / \mathrm{ac} 60111 \mathrm{a} 017$.

EPSTEIN, E. Nutrição mineral de plantas: princípios e perspectivas. São Paulo: EDUSP, 1975. 341p.

FLEXAS, J.; MEDRANO, H. Drought-inhibition of photosynthesis in $\mathrm{C}_{3}$ plants: stomatal and non-stomatal limitations revisited. Annals of Botany, v.89, p.183-189, 2002. DOI: 10.1093/aob/ $\operatorname{mcf027.~}$

GONÇALVES, J.F. de C.; SILVA, C.E.M. da; GUIMARÃES, D.G. Fotossíntese e potencial hídrico foliar de plantas jovens de andiroba submetidas à deficiência hídrica e à reidratação. Pesquisa Agropecuária Brasileira, v.44, p.8-14, 2009. DOI: 10.1590/ S0100-204X2009000100002.

GRIEVE, C.M.; GRATTAN, S.R. Rapid assay for determination of water soluble quaternary ammonium compounds. Plant and Soil, v.70, p.303-307, 1983. DOI: 10.1007/BF02374789.

KOZLOWSKI, T.T.; PALLARDY, S.G. Physiology of woody plants. $2^{\text {nd }}$ ed. San Diego: Academic Press, 1997. 411p.

KRAMER, P.J.; BOYER, J.S. Water relations of plants and soils. San Diego: Academic Press, 1995. 495p.

LANDSBERG, J.J. Physiological ecology of forest production. London: Academic Press, 1986. 198p.

LAWLOR, D.W.; CORNIC, G. Photosynthetic carbon assimilation and associated metabolism in relation to water deficits in higher plants. Plant, Cell and Environment, v.25, p.275-294, 2002. DOI: 10.1046/j.0016-8025.2001.00814.x.

LIBERATO, M.A.R.; GONÇALVES, J.F. de C.; CHEVREUIL, L.R.; NINA JUNIOR, A. da R.; FERNANDES, A.V.; SANTOS JUNIOR, U.M. dos. Leaf water potential, gas exchange and chlorophyll a fluorescence in acariquara seedlings 
(Minquartia guianensis Aubl.) under water stress and recovery. Brazilian Journal of Plant Physiology, v.18, p.315-323, 2006. DOI: $10.1590 /$ S1677-04202006000200008.

NEPOMUCENO, A.L.; NEUMAIER, N.; FARIAS, J.R.B.; OYA, T. Tolerância à seca em plantas: mecanismos fisiológicos e moleculares. Biotecnologia Ciência e Desenvolvimento, v.23, p.12-18, 2001.

PAGTER, M.; BRAGATO, G.; BRIX, H. Tolerance and physiological responses of Phragmites australis to water deficit. Aquatic Botany, v.81, p.285-299, 2005. DOI: 10.1016/j. aquabot.2005.01.002.

PINHEIRO, H.A.; DAMATTA, F.M.; CHAVES, A.R.M.; LOUREIRO, M.E.; DUCATTI, C. Drought tolerance is associated with rooting depth and stomatal control of water use in clones of Coffea canephora. Annals of Botany, v.96, p.101-108, 2005. DOI: 10.1093/aob/mci154.

PINHEIRO, H.A.; SILVA, J.V.; ENDRES, L.; FERREIRA, V.M.; CÂMARA, C.A.; CABRAL, F.F.; OLIVEIRA, J.F.; CARVALHO, L.W.T.; SANTOS, J.M.; SANTOS FILHO, B.G. Leaf gas exchange, chloroplastic pigments and dry matter accumulation in castor bean (Ricinus communis L.) seedlings subjected to salt stress conditions. Industrial Crops and Products, v.27, p.385-392, 2008. DOI: 10.1016/j.indcrop.2007.10.003.
ROCHA, E.J.P. Balanço de umidade e influência de condições de contorno superficiais sobre a precipitação da Amazônia. 2001. 210p. Tese (Doutorado) - Instituto Nacional de Pesquisas Espaciais, São José dos Campos.

SILVA, J.R.R. Comportamento ecofisiológico de plantas jovens de andiroba (Carapa guianensis Aubl.). 2009. 40p. Dissertação (Mestrado) - Universidade Federal Rural da Amazônia, Belém.

SLAVICK, B. Methods of studying plant water relations. New York: Springer Verlag, 1974. 449p. DOI: 10.1007/978-3-64265832-7.

SUDACHKOVA, N.E.; MILYUTINA, I.L.; SEMENOVA, G.P. Influence of water deficit on contents of carbohydrates and nitrogenous compounds in Pinus sylvestris L. and Larix sibirica Ledeb. tissues. Eurasian Journal of Forest Research, v.4, p.1-11, 2002.

SZABADOS, L.; SAVOURÉ, A. Proline: a multifunctional amino acid. Trends in Plant Science, v.15, p.89-97, 2010. DOI: 10.1016/j.tplants.2009.11.009.

WARREN, C.R.; ARANDA, I.; CANO, F.J. Responses to water stress of gas exchange and metabolites in Eucalyptus and Acacia spp. Plant, Cell and Environment, v.34, p.1609-1629, 2011. DOI: $10.1111 /$ j.1365-3040.2011.02357.x.

Recebido em 15 de junho de 2012 e aprovado em 18 de janeiro de 2013 